\title{
Species Difference in Plasma Insulin Responses to Intravenous Xylitol in Man and Several Mammals
}

\author{
TAKeshi KUZUYA*, YasUnORI KANAZAWA*, MitsuaKi HAYASHI**, \\ MASATOSHI KIKUCHI* AND TAKEHIKO IDE* \\ *Third Department of Internal Medicine, Faculty of Medicine, \\ University of Tokyo, Hongo, Tokyo \\ and \\ **Hokkaido Branch of National Institute of Animal Health, \\ Hitsuji-ga-oka, Sapporo
}

\begin{abstract}
Synopsis
Glucose and xylitol were administered intravenously to man and several mammals in the same doses, and the plasma insulin responses were compared. Marked species differences were found. In man, $12 \mathrm{~g}$ or $30 \mathrm{~g}$ of glucose produced definitely greater rises of plasma insulin than xylitol. In cows and goats, both $0.2 \mathrm{~g} / \mathrm{kg}$ glucose and xylitol increased plasma insulin markedly and to a similar extent. Plasma insulin responses of horses to $0.2 \mathrm{~g} / \mathrm{kg}$ glucose and xylitol were rather sluggish and poor. In rabbits, the peak insulin levels following $0.2 \mathrm{~g} / \mathrm{kg}$ glucose and xylitol were approximately similar or slightly higher after glucose, but with the dose of $1.0 \mathrm{~g} / \mathrm{kg}$, the peak plasma insulin value after xylitol was a little higher than after glucose. In rats, glucose produced higher insulin peaks than xylitol both at the doses of $0.2 \mathrm{~g} / \mathrm{kg}$ and $1.0 \mathrm{~g} / \mathrm{kg}$. These results are in contrast to the results obtained in dogs, in which xylitol has a definitely stronger insulin-releasing effect than glucose. The cause for this species variation is not explained at present.
\end{abstract}

Xylitol has a stronger stimulatory effect on insulin secretion than glucose in dogs (Kuzuya et al., 1966; 1969; Hirata et al., 1966; 1968). Its insulin-releasing effect was also demonstrated in the isolated rat islet in vitro (Montague and Taylor, 1968). In man, however, a relatively small or no increase in plasma insulin concentration was observed following the intravenous administration of xylitol (Kuzuya et al., 1967; Geser et al., 1967). Recently, Wilson and Martin (1970) demonstrated that the insulinotropic effect of xylitol was less marked than that of glucose in rhesus monkeys. In view of the discrepancy in insulin responses in these previous results, we investigated the insulinotropic effect of xylitol in several different mammal species. Equivalent doses of glucose and xylitol were given intravenously to cows, goats, horses, rabbits, rats, dogs and also to healthy human volun-

Received for publication June 14, 1971. teers. The results revealed that the relative plasma insulin responses to xylitol and glucose differed markedly among different species.

\section{Methods}

\section{Human experiments}

Volunteers consisted of healthy male students and doctors, 21-37 years of age, weighing $55-73 \mathrm{~kg}$, with no history of diabetes or metabolic diseases. None of them were obese. The experiments were performed in the morning after overnight fast. They had reclined supine for about half an hour before the first blood sampling. Indwelling needles filled with $10 \%$ solution of sodium citrate were inserted into both arm veins. After taking two control samples at 10-15 $\mathrm{min}$ intervals through one of these needles, $12 \mathrm{~g}$ or $30 \mathrm{~g}$ ( $40 \mathrm{~m} l$ of $30 \%$ or $60 \mathrm{~m} l$ of $50 \%$ solution) of glucose or xylitol was administered through another needle over $3 \mathrm{~min}$ (for $12 \mathrm{~g}$ ) or $10 \mathrm{~min}$ (for $30 \mathrm{~g}$ ). 10-12 blood samples were withdrawn for $90 \mathrm{~min}$ after the injection.

\section{Animal experiments}

Cows, goats, horses and rabbits were subjected to 
the experiments without anesthesia after an overnight fast. The weight and sex of these animals are shown in each figure. In cows, goats and horses, blood was taken through a Teflon indwelling canula inserted into the jugular vein. In rabbits, blood was collected directly into glass tubes from a cut on the ear vein. About 10 blood samples, each 2-4 ml, were collected before and after the administration of glucose or xylitol to each species. Wistar-strain rats weighing 300-500 g were used after fasting for 4-5 hr. After anesthesia with the intraperitoneal injection of about $30 \mathrm{mg} / \mathrm{kg}$ sodium pentobarbital, a thin polyethylene catheter, filled with dilute heparin in saline, was inserted into the jugular or femoral vein for blood sampling. About 30 min later, glucose or xylitol solution was injected into the jugular vein and 3-5 samples (0.8-1.0 $\mathrm{m} l$ each) were collected before and after the injection from each animal.

Glucose and xylitol were given intravenously in a dose of $0.2 \mathrm{~g} / \mathrm{kg}$ or $1.0 \mathrm{~g} / \mathrm{kg}$ in $10-50 \%$ solution. Except for rabbits and rats, the same individual animals were tested twice at an interval of 1-2 weeks with the equivalent doses of both glucose and xylitol. The order of glucose and xylitol experiments was randomized. Cows and horses were given the injection by infusion into the jugular vein within $10 \mathrm{~min}$. The injection took 2-3 min for goats, and less than one minute for rabbits and rats. The end of injection was designated as zero time for all species.

Both in man and animal experiments, blood samples were collected into glass tubes containing heparin powder, and centrifuged within one hour. The plasma was kept at $-20^{\circ} \mathrm{C}$ for subsequent analysis.

\section{Measurements of glucose, xylitol and insulin}

After deproteinization with $\mathrm{Ba}(\mathrm{OH})_{2}-\mathrm{ZnSO}_{4}$ (Somogyi, 1945), glucose was determined by a glucoseoxidase method and xylitol by a periodate oxidation method as described elsewhere (Kuzuya et al., 1969). Plasma insulin was measured by a double-antibody radioimmunoassay (Kanazawa et al., 1966), with the standard insulin of each animal species, except for the goat samples which were assayed with a pork insulin standard. Anti-pork insulin serum was used for all assays.

Prior to the immunoassay, the optimal condition for immunoprecipitation by the second precipitating rabbit antiserum was carefully selected to insure maximum precipitation in the presence of plasma of each animal species.

\section{Results}

Intravenous administration of $12 \mathrm{~g}$ or $30 \mathrm{~g}$
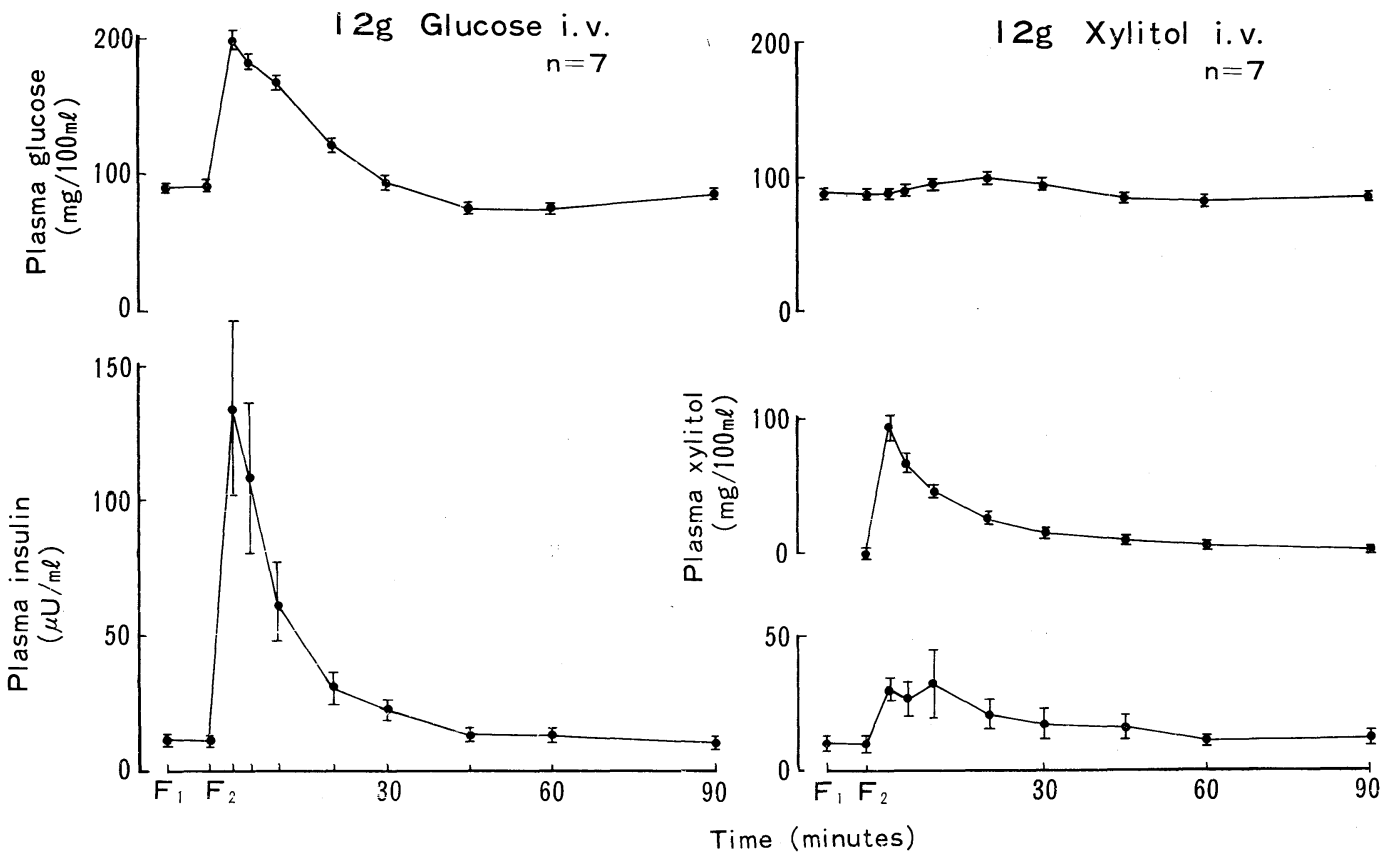

Fig. 1. Changes in plasma glucose, xylitol and insulin concentrations (mean $\pm \mathrm{SE}$ ) following intravenous administration of $12 \mathrm{~g}$ glucose or xylitol in 7 male volunteers. 


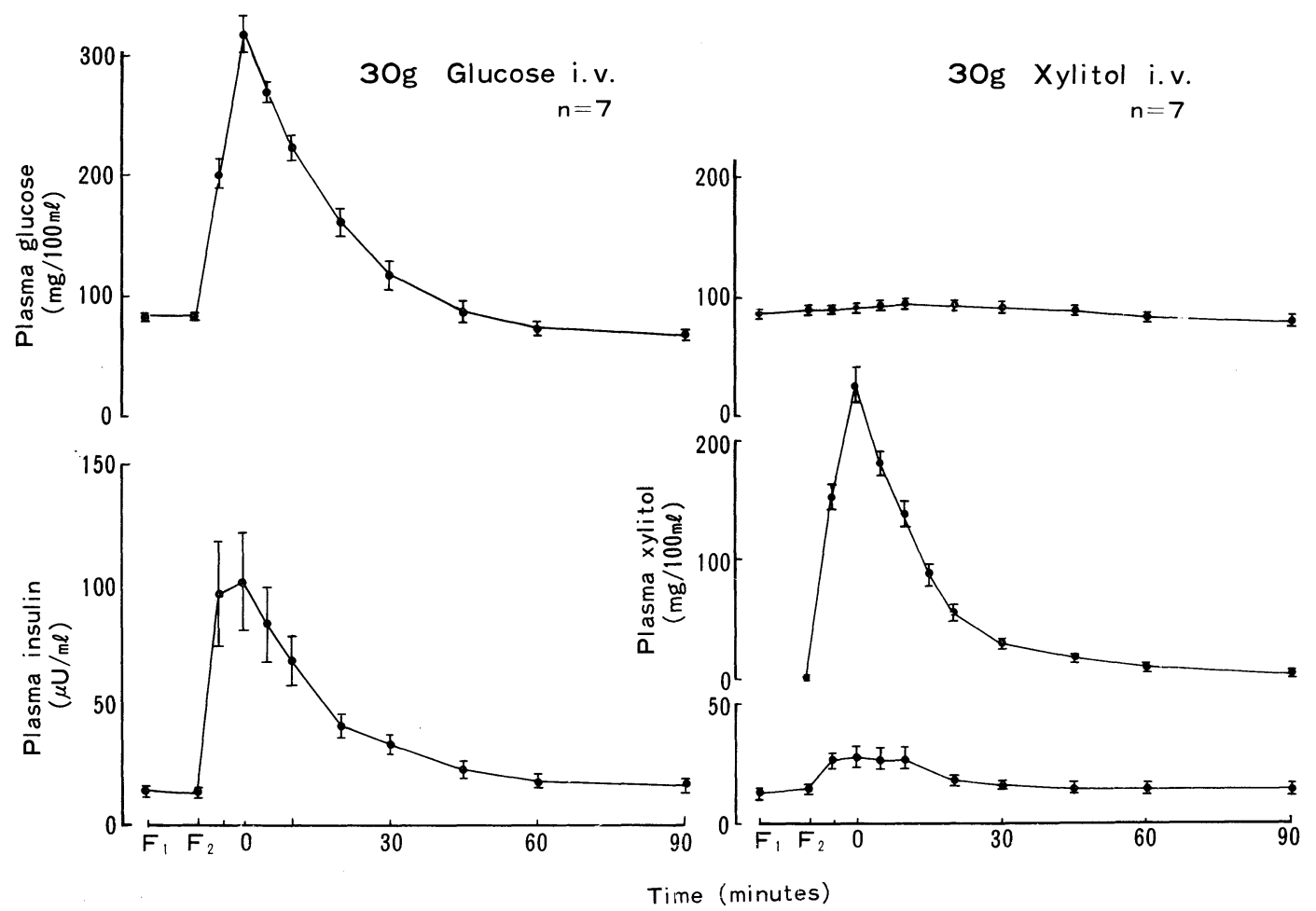

Fig. 2. Changes in plasma glucose, xylitol and insulin concentrations (mean $\pm \mathrm{SE}$ ) following intravenous administration of $30 \mathrm{~g}$ glucose or xylitol in 7 male volunteers.

of glucose or xylitol to man (Figs. 1 and 2)

The effects of the same doses of glucose and xylitol were compared in the same subjects, but the experiments with $12 \mathrm{~g}$ and $30 \mathrm{~g}$ were conducted in different groups. These doses corresponded approximately to 0.2 and 0.5 $\mathrm{g} / \mathrm{kg}$.

Infusion of glucose increased plasma glucose and insulin immediately. The peak insulin levels were $31-288 \mu \mathrm{U} / \mathrm{m} l$ after $12 \mathrm{~g}$ and 55$230 \mu \mathrm{U} / \mathrm{m} l$ after $30 \mathrm{~g}$ glucose. The plasma glucose returned to the fasting level in $30 \mathrm{~min}$ after $12 \mathrm{~g}$ glucose and in $45 \mathrm{~min}$ after $30 \mathrm{~g}$ glucose. The return of plasma insulin was also slightly delayed following a higher dose.

Following xylitol administration, plasma glucose did not change or slightly increased. Plasma xylitol reached 79-129 and 171-295 $\mathrm{mg} / 100 \mathrm{ml}$ after $12 \mathrm{~g}$ and $30 \mathrm{~g}$ xylitol respectively, and disappeared mostly in 60-90 min.
Plasma insulin increased in all cases but to a very variable extent. The peaks were $15-113$ $\mu \mathrm{U} / \mathrm{m} l$ after $12 \mathrm{~g}$ xylitol and $15-46 \mu \mathrm{U} / \mathrm{m} l$ after $30 \mathrm{~g}$ xylitol. The mean plasma insulin curves were similar after administration of $12 \mathrm{~g}$ and $30 \mathrm{~g}$ xylitol.

Intravenous administration of $0.2 \mathrm{~g} / \mathrm{kg}$ glucose or xylitol to cows (Fig. 3.)

Plasma glucose concentration increased from the fasting level of $55-82 \mathrm{mg} / 100 \mathrm{ml}$ to $220-249 \mathrm{mg} / 100 \mathrm{ml}$ immediately after administration of glucose and decreased to the control level in 90-120 min. Plasma insulin concentration also increased promptly from the fasting level of $30-59 \mu \mathrm{U} / \mathrm{m} l$ to the peak of $65-480 \mu \mathrm{U} / \mathrm{ml}$ in $10 \mathrm{~min}$, and returned to the fasting level within $120 \mathrm{~min}$.

After intravenous injection of xylitol, plasma glucose increased slightly in 3 cows, 

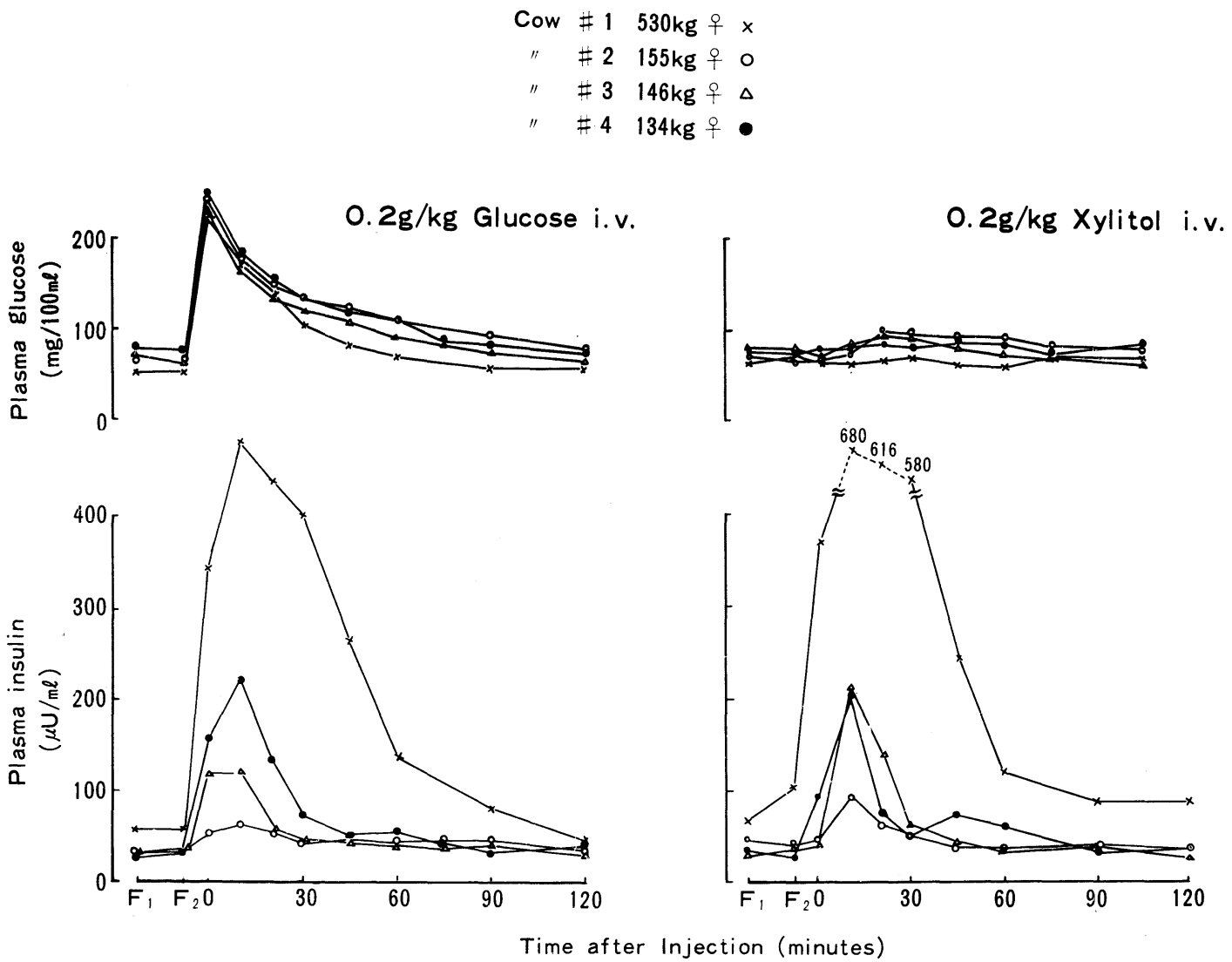

Fig. 3. Changes in plasma glucose and insulin concentrations following intravenous administration of $0.2 \mathrm{~g} / \mathrm{kg}$ glucose or xylitol in 4 cows. Different symbols represent different individuals.

and plasma insulin rose to the peak of 95 . $680 \mu \mathrm{U} / \mathrm{ml}$ in $10 \mathrm{~min}$, then decreased to the fasting level in 90-120 min. Cow no. 1 which showed the maximal insulin response to glucose was also the best responder to xylitol administration, and cow no. 2 responded least to both glucose and xylitol. Maximal insulin levels following xylitol injection were higher than those after glucose in 3 animals.

Intravenous administration of $0.2 \mathrm{~g} / \mathrm{kg}$ glucose or xylitol to goats (Fig. 4.)

After intravenous administration of glucose, plasma glucose increased from the fasting value of $59-68 \mathrm{mg} / 100 \mathrm{~m} /$ to $264-283 \mathrm{mg} / 100$ $\mathrm{m} l$, then decreased gradually. Plasma insulin level was $52-97 \mu \mathrm{U} / \mathrm{ml}$ at fasting. It reached the peak of $111-291 \mu \mathrm{U} / \mathrm{ml}$ at $10 \mathrm{~min}$ after injection, and returned to the fasting level in 60-90 min.

Following intravenous administration of xylitol, plasma glucose rose slightly. Plasma insulin increased markedly, reaching the maximum of $114-385 \mu \mathrm{U} / \mathrm{m} l$ in $10-30 \mathrm{~min}$. In 3 animals the maximal plasma insulin levels after xylitol injection were higher than those after glucose. Plasma xylitol reached 116-329 $\mathrm{mg} / 100 \mathrm{ml}$ immediately after injection, then decreased promptly.

Intravenous administration of $0.2 \mathrm{~g} / \mathrm{kg}$ glucose or xylitol to horses (Fig. 5.) 


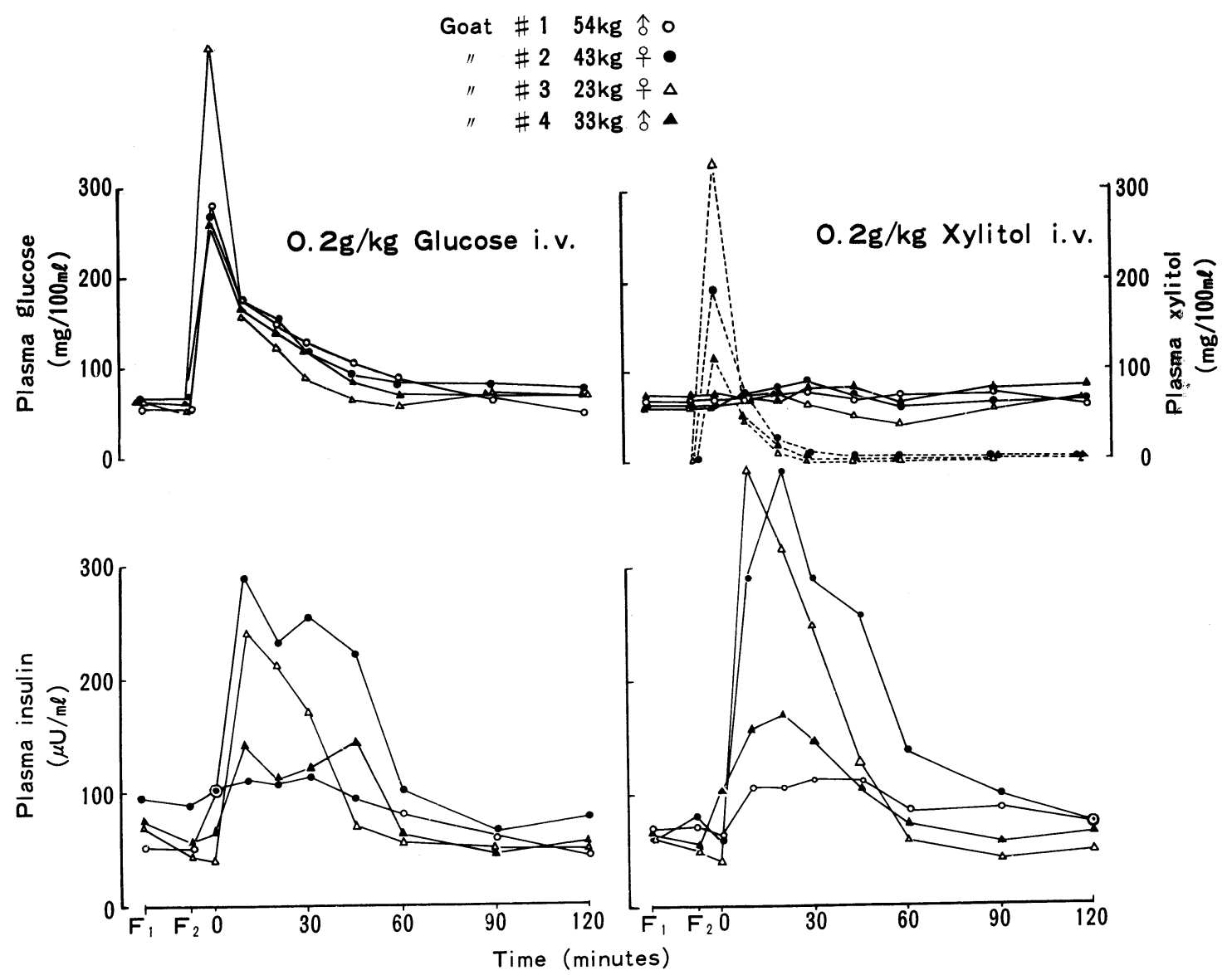

Fig. 4. Changes in plasma glucose, xylitol (dotted line) and insulin concentrations following intravenous administration of $0.2 \mathrm{~g} / \mathrm{kg}$ glucose or xylitol in 4 goats. Different symbols represent different individuals.

Plasma glucose increased from the fasting level of $82-94 \mathrm{mg} / 100 \mathrm{ml}$ to $222-243 \mathrm{mg} / 100$ $\mathrm{m} l$ after intravenous injection of glucose, and then gradually decreased, but remained higher than the fasting level even at $120 \mathrm{~min}$. The increase in plasma insulin after glucose injection was rather sluggish, and it was not clear in horse no. 3 .

Intravenous administration of xylitol caused slight or moderate rises of plasma glucose. Plasma insulin increased slightly and slowly in horses no. 1 and no. 2, but did not rise in horse no. 3. Plasma xylitol reached a peak of $129-136 \mathrm{mg} / 100 \mathrm{ml}$ immediately after injection, and disappeared from the circula- tion within $60 \mathrm{~min}$.

Intravenous administration of 0.2 or 1.0 $\mathrm{g} / \mathrm{kg}$ of glucose or xylitol to rabbits (Figs. 6 and 7)

These unanesthetized rabbits had fairly high and variable fasting plasma glucose levels. Following injection of $0.2 \mathrm{~g} / \mathrm{kg}$ glucose, plasma glucose reached $250-330 \mathrm{mg} / 100 \mathrm{ml}$, and returned to the control level in $60 \mathrm{~min}$. Injection of $0.2 \mathrm{~g} / \mathrm{kg}$ xylitol caused slight or moderate rises in plasma glucose. Plasma xylitol reached 131-255 $\mathrm{mg} / 100 \mathrm{ml}$ immediately after xylitol injection and almost disappeared in $60 \mathrm{~min}$. Plasma insulin reached 


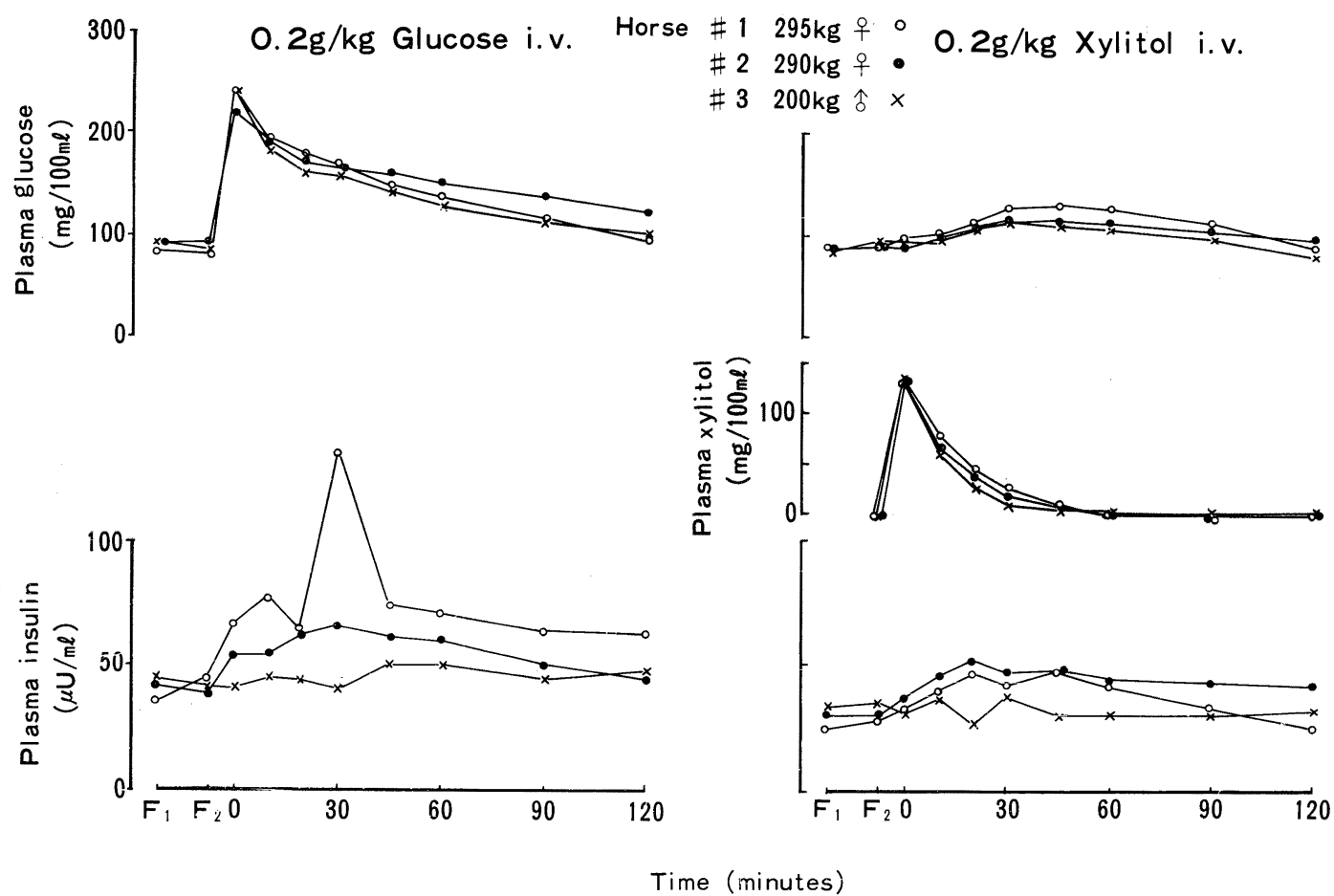

Fig. 5. Changes in plasma glucose, xylitol and insulin concentrations following intravenous administration of $0.2 \mathrm{~g} / \mathrm{kg}$ glucose or xylitol in 3 horses. Different symbols represent d'ffcrent individuals.

the peak of $13-57 \mu \mathrm{U} / \mathrm{m} l$ at 0 or 10 min after administration of $0.2 \mathrm{~g} / \mathrm{kg}$ glucose, and of $11-44 \mu \mathrm{U} / \mathrm{ml}$ at 10 minutes after $0.2 \mathrm{~g} / \mathrm{kg}$ xylitol.

Following intravenous administration of $1.0 \mathrm{~g} / \mathrm{kg}$ glucose, plasma glucose increased to $529-607 \mathrm{mg} / 100 \mathrm{~m} l$ and plasma insulin reached a peak of $19-118 \mu \mathrm{U} / \mathrm{m} l$ in $0-5 \mathrm{~min}$. Intravenous administration of $1.0 \mathrm{~g} / \mathrm{kg}$ xylitol caused variable rises in both plasma glucose and plasma insulin. Plasma insulin reached a peak of $42-151 \mu \mathrm{U} / \mathrm{m} l$ between $30-45 \mathrm{~min}$ after injection, which was delayed in comparison with the peak after the injection of glucose. Plasma xylitol rose to $347-398 \mathrm{mg} / 100$ $\mathrm{m} l$ following injection, and declined thereafter approaching the baseline in $120 \mathrm{~min}$.

Intravenous administration of 0.2 or 1.0 $\mathrm{g} / \mathrm{kg}$ of glucose or xylitol to rats (Figs.

\section{8 and 9)}

Plasma glucose ranged from 111 to 146 $\mathrm{mg} / 100 \mathrm{~m} l$ before injection of glucose or xylitol. It rose to $169-241$ or $435-568 \mathrm{mg} / 100$ $\mathrm{ml}$ following 0.2 or $1.0 \mathrm{~g} / \mathrm{kg}$ glucose, and returned to the control level in 30 or 60 minutes. When glucose was given, plasma insulin increased from $13-56 \mu \mathrm{U} / \mathrm{m} l$ to $31-192$ $\mu \mathrm{U} / \mathrm{m} l$ after $0.2 \mathrm{~g} / \mathrm{kg}$ and to $35-264 \mu \mathrm{U} / \mathrm{m} l$ after $1.0 \mathrm{~g} / \mathrm{kg}$ within $5 \mathrm{~min}$, then decreased. Following administration of xylitol, plasma glucose tended to increase slightly or remain unchanged, and plasma xylitol reached 43-70 $\mathrm{mg} / 100 \mathrm{ml}$ after $0.2 \mathrm{~g} / \mathrm{kg}$ and $303-431 \mathrm{mg} / 100$ $\mathrm{m} /$ after $1.0 \mathrm{~g} / \mathrm{kg}$, respectively. The peak insulin concentrations were $45-103 \mu \mathrm{U} / \mathrm{m} l$ after 0.2 $\mathrm{g} / \mathrm{kg}$ xylitol and $54-108 \mu \mathrm{U} / \mathrm{m} l$ after $1.0 \mathrm{~g} / \mathrm{kg}$ xylitol. The peak of insulin response curve was slightly delayed after a higher dose of xylitol but not after a higher dose of glucose. 
$0.2 \mathrm{~g} / \mathrm{kg}$ Glucose i.v.
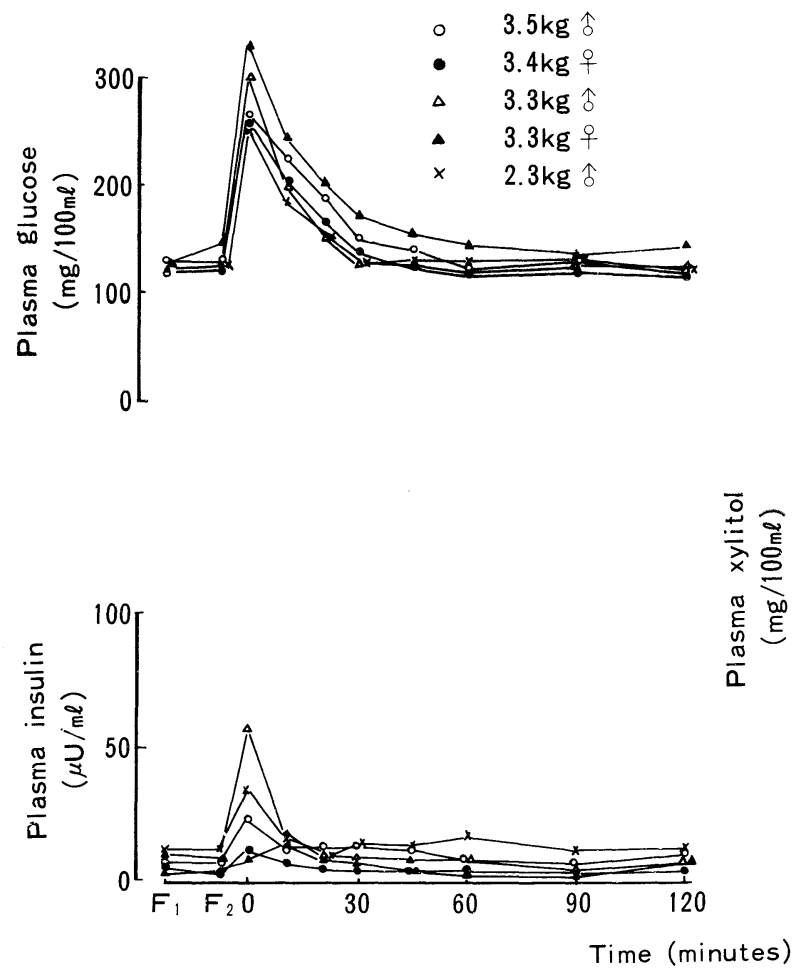

$0.2 \mathrm{~g} / \mathrm{kg}$ Xylitol i.v.
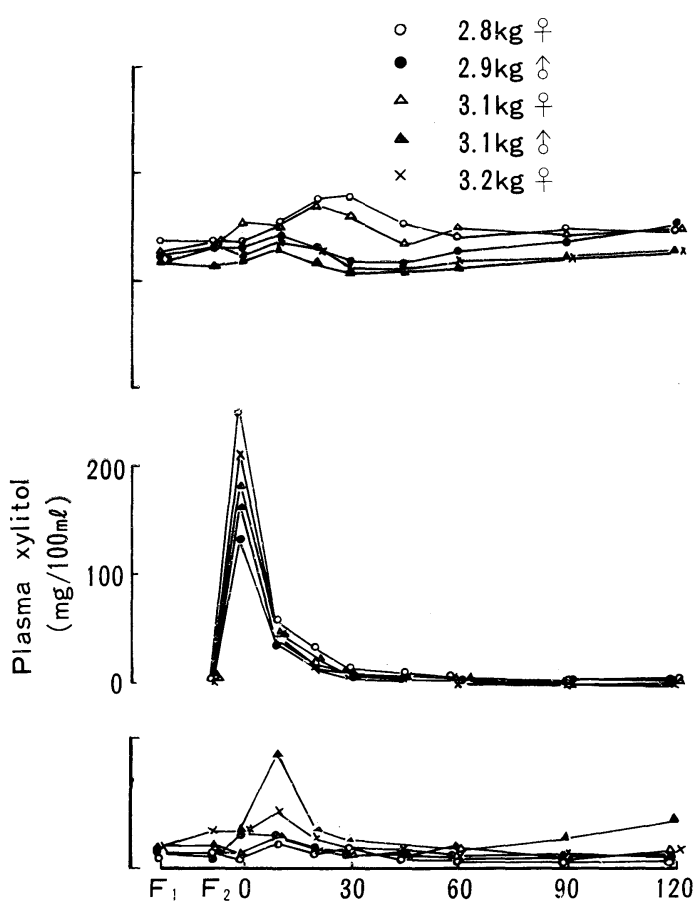

Fig. 6. Changes in plasma glucose, xylitol and insulin concentrations following intravenous administration of $0.2 \mathrm{~g} / \mathrm{kg}$ glucose or xylitol in 5 rabbits. Different symbols represent different individuals.

\section{Discussion}

Although the secretory response of insulin to various stimuli has been investigated in a variety of conditions both in vivo and in vitro, only a few reports have dealt with the differences in insulin secretion among different animal species. However, some previous studies did suggest that the insulinotropic effects of some substances are not uniform in various animal species. For example, intravenous galactose increases plasma insulin in sheep (Boda, 1964), but not in man (Karam et al., 1966). Some short chain fatty acids are reported to stimulate insulin secretion strongly in sheep and cows, but have no effect in rats, rabbits and pigs (Horino et al., 1968). In the present study, we compared the relative insulinotropic potencies of intravenous glucose and xylitol in several mammals including man. We gave these two substances on the same weight dose basis. As xylitol has a smaller molecular weight, these doses are not equimolar, but the number of carbon atoms per the same weight are approximately the same.

Glucose is usually considered as a common and most important physiological factor controling insulin secretion in mammals, and its insulinotropic effect has been confirmed in many species. An increase in plasma insulin after a glucose load was observed in all the species tested in this study, but the degree of hyperinsulinemia from the same dosage per body weight was markedly different between different species. The insulinotropic effects of 


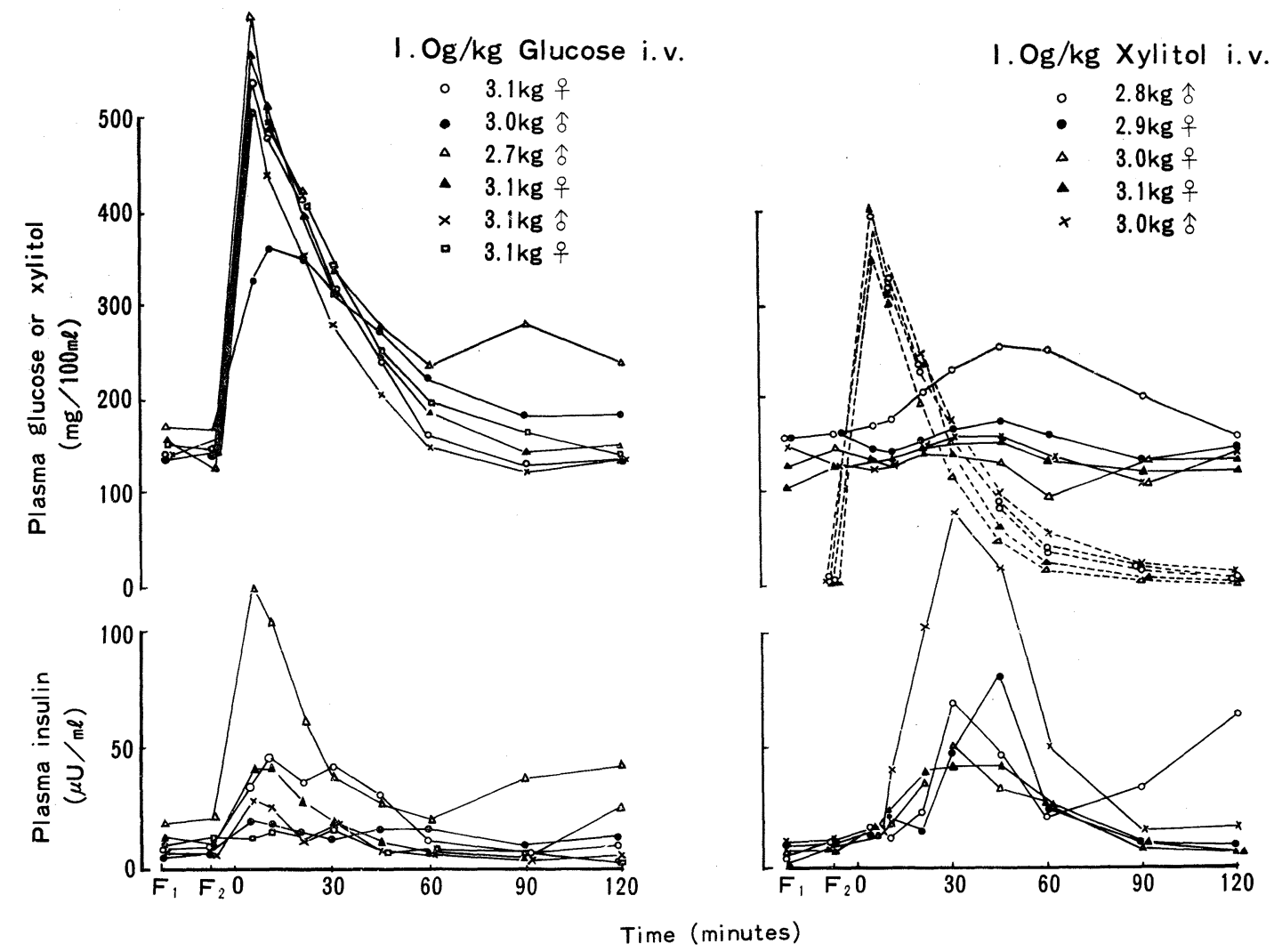

Fig. 7. Changes in plasma glucose, xylitol (dotted line) and insulin concentrations following intravenous administration of $1.0 \mathrm{~g} / \mathrm{kg}$ glucose or xylitol in 5-6 rabbits. Different symbols represent different individuals.

xylitol were also observed in all the animals except horses in which the rise of plasma insulin was not significant. These data suggest that insulin-releasing effect of xylitol is fairly widely distributed in mammals. However, species variability in the effects of xylitol appears much greater than that of glucose. Among animals studied so far, dogs are the most responsive animal to xylitol administration. Man is a poor responder to xylitol, and horses responded weakly both to xylitol and glucose (Fig. 10). Rhesus monkeys also appear to be poor responders to xylitol (Wilson and Martin, 1970).

Our data show that the responsiveness to these stimuli is variable even in the same species. Within the same species, there ap- peared to be a general tendency that an individual which responded well to glucose with a marked rise to plasma insulin responded well also to xylitol. Such individual variation of plasma insulin responses to xylitol was also observed in the experiments on man.

As glucose and xylitol were given to cows, horses and goats only in a dose of $0.2 \mathrm{~g} / \mathrm{kg}$, the relative insulin-releasing potencies of glucose and xylitol in a larger dose is unknown. In rabbits, glucose produced a little larger effect than xylitol at $0.2 \mathrm{~g} / \mathrm{kg}$, while xylitol caused a greater hyperinsulinemia than glucose when $1.0 \mathrm{~g} / \mathrm{kg}$ was given. The doseresponse relationships of the insulin-releasing effect of xylitol are particularly remarkable in dogs (Kuzuya et al., 1969). At $0.05-0.1 \mathrm{~g} / \mathrm{kg}$, 


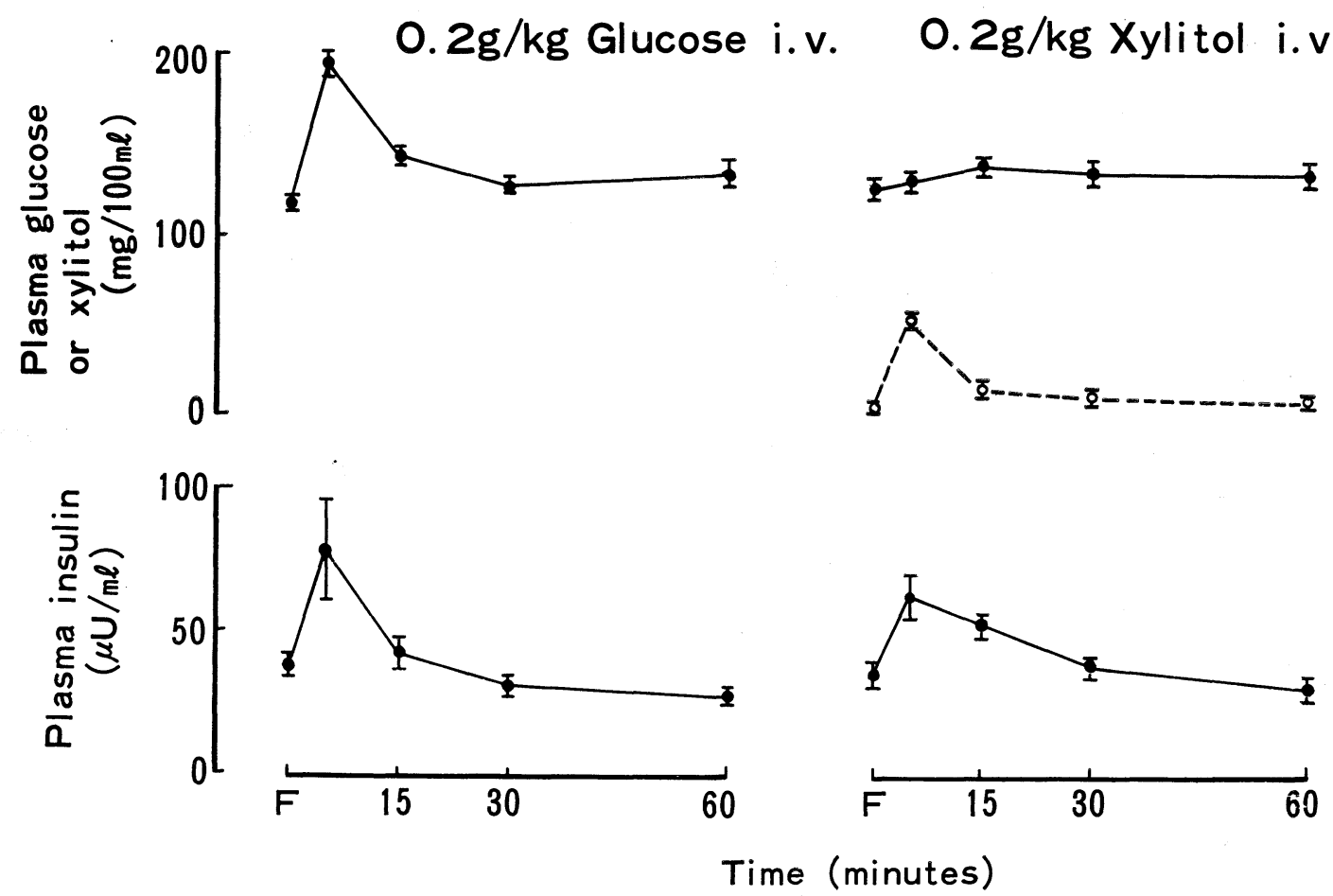

Fig. 8. Changes in plasma glucose, xylitol (dotted line) and insulin concentrations following intravenous administration of $0.2 \mathrm{~g} / \mathrm{kg}$ glucose or xylitol in anesthetized rats. Each value represents the mean \pm SE of 5-9 experiments.

glucose and xylitol produce approximately similar increases in plasma insulin, while with doses more than $0.2 \mathrm{~g} / \mathrm{kg}$, xylitol produced much greater effect than glucose. Such dosedependency was not so clear in rats or in man. However, it seems possible that the insulinemic effect of xylitol in some other animals might be more pronounced if it is given in larger doses.

Although a direct effect on the pancreas was suggested both for glucose and xylitol in vivo (Kuzuya and Kanazawa, 1969) and in vitro (Montague and Taylor, 1968), there was some difference between the patterns of insulin responses following large doses of glucose and xylitol. In most animals, plasma insulin reached a peak within 10 minutes after injection of glucose, irrespective of dose, whereas the maximal plasma insulin level following $1.0 \mathrm{~g} / \mathrm{kg}$ xylitol appeared at $15-30$ min or later in rats, rabbits and dogs. This fact may suggest that xylitol has some additional effect in vivo for promoting insulin secretion.

One of the current concepts for the mechanism of insulin secretion by sugars is that sugars must be metabolized within the islet cells to stimulate insulin release (Coore and Randle, 1964; Montague and Taylor, 1969). Consequently, it is possible that species differences of plasma insulin responses to glucose and xylitol are caused by the species differences in the metabolism of these two substances in the islet cells. Ruminant animals which utilize short-chain fatty acids as a primary sourse for body energy, respond to short-chain fatty acids with a greater rise of plasma insulin than after glucose (Horino et al., 1968). However, it is also possible that the physiological effect of overnight fast may differ between ruminant and non-ruminant, 

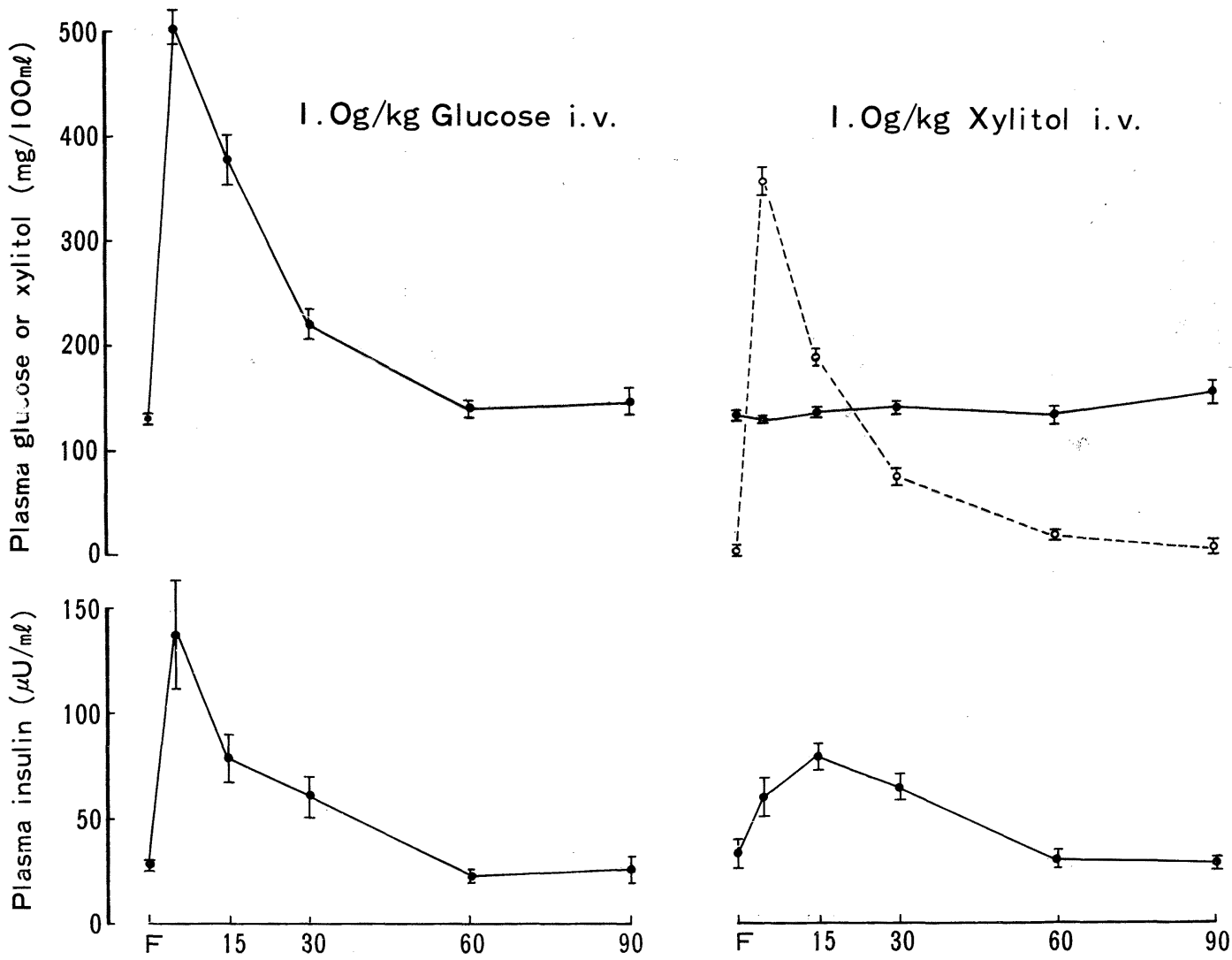

Time (minutes)

Fig. 9. Changes in plasma glucose, xylitol (dotted line) and insulin concentrations following intravenous administration of $1.0 \mathrm{~g} / \mathrm{kg}$ glucose or xylitol in anesthetized rats. Each value represents the mean \pm SE or 5-9 experiments.

or between big or small-sized animals. Thus, the difference in basal conditions of various animal species may have contributed to the observed difference in insulin response to some extent. However, the ability of xylitol to release insulin seems to be unrelated to the size of animals, whether or not they are ruminant, and whether they are herbivorous or carnivorous. Our few preliminary experiments suggest that insulin secretion by xylitol is not marked in cats. Lack of information about the metabolic characteristics of islet cells of each species precludes a precise explanation of our results. However, these data indicate that precautions are needed, in the investigation of insulin secretion, to extend the conclusion obtained in one animal, to other animal species.

\section{Acknowledgements}

We thank Professor K. Nakao for his support and Dr. D. Porte, Jr. for his criticism in the preparation of the manuscript. Xylitol was kindly donated by Eisai and Co., Koishikawa, Tokyo. We are also grateful to Mr. H. Ege, NOVO Terapeutisk Laboratorium, Copenhagen and Mr. Y. Koga, Shimizu Seiyaku Company for the supply of standard insulins of various animal species. The technical assistance of Mr. S. Nagayama is much acknowledged. 

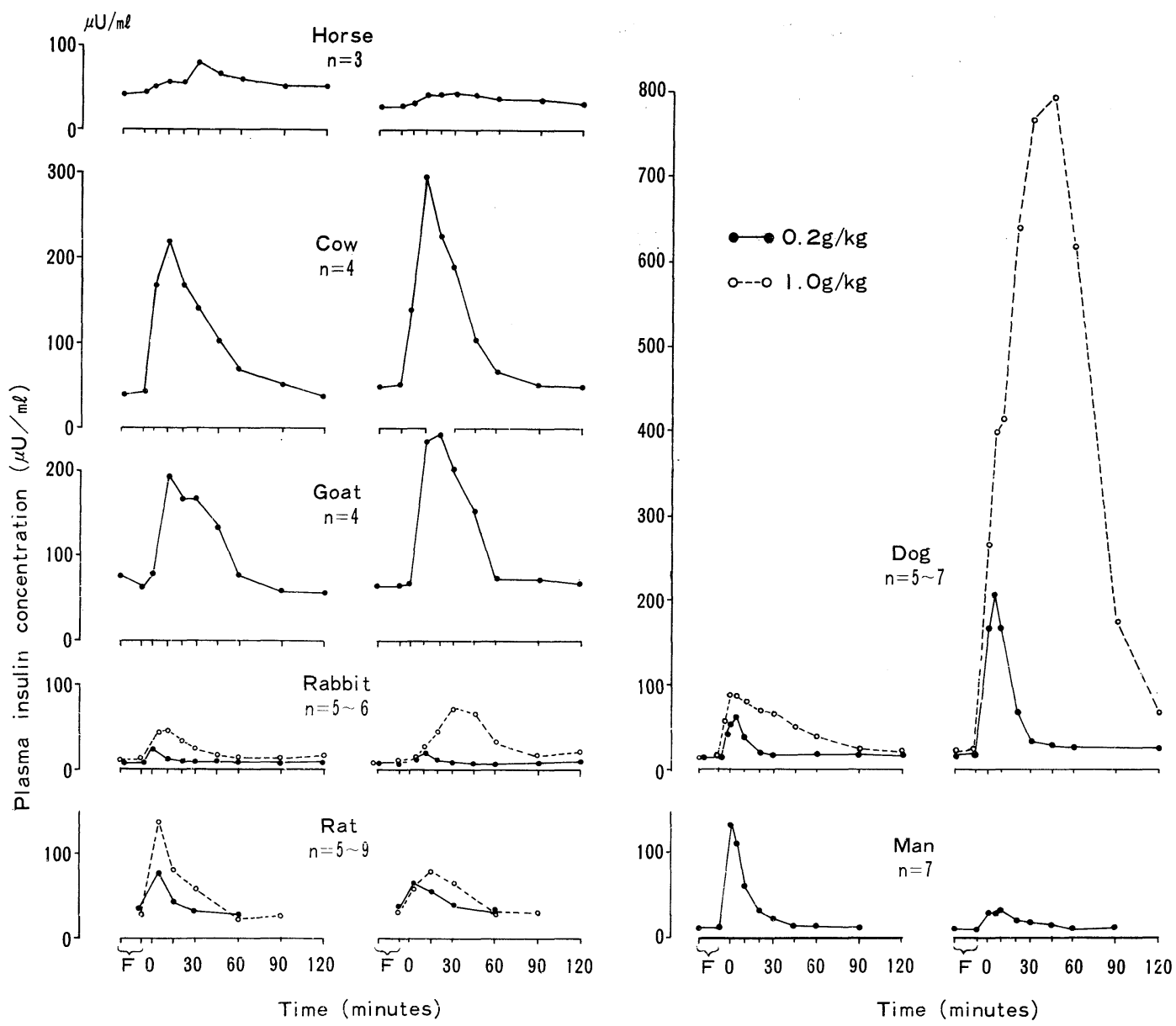

Fig. 10. Comparison of mean plasma insulin curves following intravenous administration of $0.2 \mathrm{~g} / \mathrm{kg}$ or $1.0 \mathrm{~g} / \mathrm{kg}$ of glucose (left) or xylitol (right) in man and several mammals.

\section{References}

Boda, J. M. (1964). Amer. J. Physiol. 206, 419.

Coore, H. G. and P. J. Randle (1964). Biochem. J. 93, 66.

Geser, K. A., H. Förster, H. Pröls and H. Mehnert (1967). Klin. Wschr. 45, 851.

Hirata, Y., M. Fujisawa, H. Sato, T. Asano and S. Katsuki (1966). Biochem. Biophys. Res. Commun. 24, 471.

Hirata, Y., M. Fujisawa, H. Sato, T. Asano and S. Katsuki (1968). Z. ges. exper. Med. 145, 111.

Horino, M., L. J. Machlin, R. Hertelendy, and D. M. Kipnis (1968). Endocrinology 83, 118.

Kanazawa, Y., T. Kuzuya, T. Ide, and K. Kosaka (1966). Amer. J. Physiol. 211, 442.

Karam. J. H., S. G. Grasso, L. C. Wegienka, G. M. Grodsky, and P. H. Forsham (1966). Diabetes 15, 571.

Kuzuya, T. and Y. Kanazawa (1969). Diabetologia 5, 248.

Kuzuya, T., Y. Kanazawa, and K. Kosaka (1966). Metabolism 15, 1149. 
Kuzuya, T., Y. Kanazawa, and K. Kosaka (1969). Endocrinology 84, 200.

Kuzuya, T., Y. Kanazawa, M. Shimoshige, and K. Kosaka. Excerpta Medica International Congress Series No. 140, 77 (1967).

Montague, W. and K. W. Taylor (1968).
Biochem. J. 109, 333.

Montague, W. and K. W. Taylor (1969). Ibid. 115, 257.

Somogyi, M. (1945). J. Biol. Chem. 160, 69. Wilson, R. B. and J. M. Martin (1970). Diabetes 19, 17. 